\title{
LA CONSTITUCIÓN ECONÓMICA SOCIALISTA Y SUS FUNDAMENTOS ${ }^{1}$
}

\author{
Lissette Pérez Hernández
}

doi: 10.18543/ed-64(1)-2016pp61-95

\begin{abstract}
Sumario: 1. Algunas notas introductorias. 2. Fundamentos De LA CONSTITUCIÓN ECONÓMICA DE TIPO SOCIALISTA. 2.1. Intervención estatal en la economía. 2.2. Intervención estatal en la economía. 2.3. Intervención estatal en la economía. 2.4. Intervención estatal en la economía. 2.5. Intervención estatal en la economía. 3. EL MODELO SOCIALISTA DE EUROPA DEL ESTE. UN BREVE REPASO A ALGUNAS CAUSAS ECONÓMICAS DE SU DERRUMBE. 4. PARTICULARIDADES DE LA REGULACIÓN CONSTITUCIONAL DE LA ECONOMÍA EN LA REPÚBLICA SOCIALISTA DE VIETNAM. 5. CARACTERÍSTICAS CONSTITUCIONALES ESENCIALES del Modelo Económico Cubano. 6. Algunas líneas para la reFLEXIÓN EN POS DEL PERFECCIONAMIENTO DE LA CONSTITUCIÓN ECONÓmica Cubana. 7. La Constitución ECONÓmica Socialista EN EL SIGLO XXI. 8. CONSIDERACIONES FINALES.
\end{abstract}

\section{ALGUNAS NOTAS INTRODUCTORIAS}

Los postulados constitucionales se sitúan como punto de intersección entre la política y el Derecho y como cauce democrático de la legalidad. En

1 Trabajo realizado en el marco del Proyecto de Investigación Constitución y mercado en la crisis de la integración europea. $\mathrm{I}+\mathrm{D}+\mathrm{i}$ del Programa Estatal de Investigación, Desarrollo e Innovación orientada a los Retos de la Sociedad, del Ministerio de Economía y Competitividad (DER2013-48327-C3-1-R). Investigadores principales: José Luis GARCia Guerrero y María Luz Martínez Alarcón. 
ese contexto la Constitución puede ser concebida como punto de llegada de un proceso político, como punto de partida de los ordenamientos jurídico y también como fundamento jurídico y político de la organización estatal, de los principios que rigen determinada sociedad y marcan los derroteros por donde deben transitar las relaciones del Estado con los individuos.

De la misma forma, existe una relación dialéctica y compleja muy estrecha, entre política, derecho y economía. LeNIN consideró al respecto, que la política es expresión concentrada de la economía, y le concedió mucha importancia a la legislación en la realización de la política económica, asumida como algo que concierne a todos ${ }^{2}$, mientras $\mathrm{BIKOV}^{3}$, analizando los presupuestos marxistas relacionados con el tema en cuestión, aseguró que las relaciones económicas son en sí misma, el resultado de la unidad del contenido económico y la forma jurídica que provee el derecho como instrumento organizativo.

De manera general, los propios preceptos constitucionales corroboran esas posiciones, en tanto, abordar las constituciones solo desde la tradicional división metodológica que contempla un preámbulo, una parte orgánica, otra parte dogmática y una cláusula de reforma, puede resultar hoy día insuficiente, si se tiene en cuenta que uno de los signos más característicos del constitucionalismo contemporáneo se centra en la constitucionalización de los principios reguladores de la economía, ordenadores del marco jurídico fundamental para la estructura y funcionamiento de la actividad económica ${ }^{4}$.

El referido marco jurídico se expresa por medio de normas, principios y valores que de forma dispersa o integrando una parte de la normativa constitucional, ofrecen el contenido de lo que doctrinalmente se reconoce como «Constitución económica», preceptos específicos, que tienen la función de habilitar y orientar la acción económica, sin perjuicio, de que consideremos además muy difícil, encontrar una norma o sección constitucional en la cual no influya alguna proyección de la economía, lo que sucede porque las políticas públicas, forman parte de su tiempo histórico, su trazado responde a condicionamientos diversos, entre los que figuran con notable fuerza los económicos.

Las constituciones modernas se caracterizan por diseñar un modelo de sociedad que cristalizan en tres ejes fundamentales muy relacionados entre

${ }^{2}$ LenIN, V.I., Obras completas, 2. a edición, 1971, Buenos Aires, t. 34, p. 364; Ídem, t. 35, pp. 549-550, Ídem, T. 36, pp. 441-442. Ídem, t. 35, p. 320.

3 BIKov, A.; LaJnó, P., El derecho y el mecanismo económico en la URSS, Ed: Progreso, Moscú, 1988, p. 7.

${ }^{4}$ Brewer-Carias Allan R., «Reflexiones sobre la Constitución económica», en Estudios sobre la Constitución española. Homenaje al profesor E. García de Enterría, Ed: Civitas, Madrid, 1991, pp. 3840-3842. 
sí: el sistema político, el sistema económico y los derechos y deberes fundamentales, lo que trae como consecuencia que crezcan las expectativas acerca del papel que debe desempeñar el Estado: debe ser eficaz y legítimo en las decisiones que toma, en las actividades que ejecuta, en la selección de los instrumentos que utiliza para implementar las políticas públicas, así como, en la exigencia de responsabilidad al funcionario público en el uso eficiente de los recursos del Estado, todo ello garantizando el ejercicio y disfrute de los derechos ciudadanos.

En ese sentido, de forma global y extrema, hoy día las administraciones estatales se encuentran ante la alternativa de decidir su proyección estratégica en dos direcciones fundamentales, siguen el curso de tendencias neoliberales que estimulan a reducir la participación estatal en las economías nacionales, o se inclinan por reforzar su intervención pública; mientras que, independientemente de la opción estatal que se siga, los ciudadanos exigen cada vez con mayor fuerza, el aumento de la eficacia y responsabilidad estatal en la atención a las políticas sociales.

Lo anterior significa que todo Estado tiene que adoptar por fuerza una política económica, incluso, cuando decide no intervenir en la actividad económica, y como esta no se manifiesta fuera de los marcos normativos, no sólo es importante cuántos recursos se tiene, sino también cuáles son los límites para su uso. Es por ello que la constitucionalización del trabajo de los principios que inspiran la actividad financiera, de los derechos económicos y sociales, entre otros elementos relacionados, muestra que los procesos económicos y hasta el mercado requieren de institucionalización para su organización, y de un análisis jurídico especial que permita profundizar de forma reflexiva en las normas con notabilidad económica.

La Constitución económica, al establecer la estructuración, los principios rectores y las pautas de actuación de la economía, implanta un modelo específico de Estado. Relacionado con ello, la doctrina ofrece diversas clasificaciones de los modelos económicos, en su mayoría diferenciadas por características esenciales que se destacan en su regulación y funcionamiento. De ellas, consideramos pertinente reconocer como principales ${ }^{5}$ los siguientes modelos económicos constitucionales: el de economía de mercado (priman las leyes económicas ciegas de oferta y demanda), propio de los sistemas económicos liberales, el de economía centralizada, con mayor intervencionismo y economía planificada y el de economía mixta donde se toman elementos compatibles de los anteriores y se procura satisfacer ciertos estándares de vida a los ciudadanos, aunque en realidad es una forma históricamente evolucionada y un reacomodo táctico del modelo de economía de mercado.

5 Cosculluela Montaner, L.; López Benitez, M., Derecho Público Económico, tercera edición, Ed: Iustel, Madrid, 2009. 
Con los mismos indicadores, autores como PAREJO AlFonso ${ }^{6}$, consideran que la economía se distingue a partir del papel del Estado en ellas, y plantean que desde ese punto de vista las principales formas extremas que se han presentado son: la economía planificada y la economía de mercado, la primera descansa en la centralización en el Estado como propietario único de los medios de producción, de las decisiones económicas fundamentales, articuladas mediante planes periódicos de objetivos y cobertura de necesidades, que limitan la iniciativa privada; mientras la segunda, reposa sobre el principio de autonomía privada bajo la forma de libertades de empresa, profesión y oficio y contratación y propiedad privada; descentralización de las decisiones económicas.

Los distintos modelos como alternativas diferentes del ejercicio económico, se articulan sobre la base de la combinación resultante de diferentes ejes ${ }^{7}$, a saber: la propiedad dominante, las formas de gestión de la propiedad, las fuentes y bases materiales de acumulación, los mecanismos de regulación de la producción social, la organización económica del Estado, las características de los mercados y las fuentes y formas de distribución de los ingresos.

Como es fácil apreciar desde esa línea de análisis, cuál es el papel del Estado en la economía, cómo se caracteriza el régimen de economía; cómo se definen el sistema de propiedad y las disposiciones orgánicas relacionadas con las atribuciones que norman los principales instrumentos para actuar en materia económica, son elementos que concretan la tipología de los sistemas económicos, le otorgan sentido a los proyectos económicos y conllevan determinada política social.

Con el objetivo de conducir el análisis hacia lo que consideramos debe ser la esencia constitucional que fundamente los vínculos entre el Estado y la economía permitiendo -o exigiendo- su juridicidad, hemos seleccionado como presupuesto para el análisis, la cadena lógica de razonamiento que propone la Dra. HERNÁNDEZ ${ }^{8}$, sintetizándola de la siguiente forma:

El objetivo básico de cualquier política pública es contribuir a la satisfacción de las necesidades de la población, para conseguir tal objetivo, se han utilizado diferentes procedimientos a lo largo de la historia. Cuando las fuerzas del mercado se dejan en completa libertad puede aumentar la eficiencia

${ }^{6}$ Parejo Alfonso, L., Lecciones de Derecho Administrativo. Orden Económico y sectores de referencia, 2. ' edición, Tirant lo Blanch, Valencia, 2011, p. 19.

7 AA.VV., Aprendiendo economía en Cuba. Nociones para no economistas. Universidad de La Habana, 2013, La Habana, p. 81.

8 Álvarez Hernández, O., Ponencia presentada en: X Congreso Internacional del CLAD sobre la Reforma del Estado y de la Administración Pública, Santiago, Chile, 1821 Oct. 2005. http://old.clad.org/congresos/congresos-anteriores/x-santiago-2005, consultado el 5 de julio de 2015. 
técnico-productiva, pero se generan desequilibrios, desigualdades y tensiones que ninguna sociedad mínimamente desarrollada puede tolerar, por tanto, es necesario intervenir para reducir, corregir o compensar tales ineficiencias. La intervención pública, por su parte, también implica ineficiencias, despilfarros y opacidades que hacen necesario someterla al cumplimiento de requisitos básicos tales como: eficacia, eficiencia y transparencia. Hay, pues, que establecer normas que regulen el funcionamiento del mercado, y hay, pues, que establecer mecanismos que controlen el funcionamiento de la intervención pública. A ambos efectos es necesario: renunciar a la construcción de fórmulas universales, establecer una cierta combinación de Estado y mercado, promover una cierta «complicidad» entre Estado y mercado y proceder, en todo caso, a la evaluación de políticas públicas.

En correspondencia con lo anterior, el presente trabajo se propone un análisis desde la perspectiva del derecho constitucional, una reflexión sobre algunos de los fundamentos del constitucionalismo socialista y el papel del Estado como regulador en ese contexto, sobre la base de una tesis esencial: el Estado debe tener como objetivo primero, procurar no solo riquezas, sino el bienestar de la población, por lo que debe a la par que promueve el desarro1lo, reforzar su capacidad de supervisión y control, para garantizar con ello, que las leyes económicas operen en consonancia con ese fin, porque al decir de BIDART CAMPOS: «Es indudable que, aun sin ser economistas, no resulta audaz sino obligatorio aportar criterios éticos, políticos y jurídicos, en una mínima interdisciplinariedad bien tramada, para armar un sistema económico que resulte apto a la dignidad de la persona humana» ${ }^{9}$.

\section{FUNDAMENTOS DE LA CONSTITUCIÓN ECONÓMICA DE TIPO SOCIALISTA}

En este apartado vale la pena un poco de descripción, teniendo en cuenta la poca difusión de los contenidos constitucionales socialista, en particular los que en dimensión temporal, adquieren naturaleza histórica.

El sistema económico ${ }^{10}$ socialista descansa a partir de los fundamentos marxistas que le sirven de base y los postulados de la constituciones al respecto: en la propiedad estatal sobre los medios de producción fundamentales, en la planificación como regulación directa de la actividad económica y en la distribución con arreglo al trabajo aportado, «de cada cual según su capaci-

9 Bidart Campos, G. J., La Constitución económica. Fundación Universitaria de Derecho, Administración y Política, 2003, México, p. 37.

${ }^{10}$ Entendido el sistema económico, como el sistema de normas y principios que tienen por objeto establecer el marco regulatorio que le permite al Estado dirigir o participar como actor en los principales procesos económicos de un país. 
dad; a cada cual, según su trabajo,» conforme al modelo propio que en correspondencia con determinadas condiciones, cada país ha puesto en marcha.

La naturaleza de la economía que diseña el sistema socialista demanda la integración del derecho a la vida económica. En ese contexto, el Derecho es resorte de la producción y la economía, motivo por el cual, los postulados de tipo socialista se caracterizan por la regulación, planificación y control central de la actividad económica, la existencia de decisiones de autoridad que debe erigirse sobre la base de las necesidades del ciudadano y por un sistema de propiedad, en el que prevalece la propiedad estatal sobre otros tipos de propiedad que con ella pueden convivir. Veamos algunos de los principios cardinales en los que se asentaron la mayoría de las Constituciones socialistas, en particular, hasta la década de los 90 del pasado siglo:

\subsection{Intervención estatal en la economía}

La intervención estatal en la economía socialista se aprecia con connotación particular. Se traduce en el dominio por parte del Estado del espacio económico al serle atribuidas constitucionalmente las funciones económicas y de regulación social, a órganos que lo conforman. El papel económico del Estado como centro político y económico del sistema, se corresponde con la naturaleza de la producción y la participación de sus organismos en la gestión de la economía.

La dirección de la economía consagrada en las constituciones socialistas, conjuga la administración centralizada, con cierta independencia e iniciativa económica de las empresas y otras entidades. LENIN ${ }^{11}$ escribió al respecto, enfatizando en la necesidad de asegurar la autonomía de las empresas en la disposición de los recursos financieros y materiales, con indicación precisa sobre la garantía de los derechos de las empresas y la responsabilidad que recae en las instituciones centrales por frenar la iniciativa local o apoyarla insuficientemente.

El Estado asume funciones como la salud, la educación, la seguridad social, comunicaciones, transporte, etcétera y mantiene una fuerte intervención en la actividad jurídico privada, por medio de técnicas administrativas como la ordenación, la promoción, el fomento y la fiscalización de la actividad económica, extendiendo su accionar fuera de los marcos que conceden otros sistemas económicos sociales.

En consecuencia, es atribución estatal, regular, disciplinar y ejecutar la política económica y la planificación, con el objetivo de equilibrar las necesidades sociales y los recursos materiales disponibles, mediante las diferen-

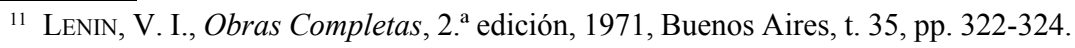


tes políticas estatales y normativas jurídicas relacionadas con aspectos del quehacer económico. La legislación estatal provee el marco normativo e institucional dentro del cual se desempeña la economía, a partir de la cual, el Estado asume de forma directa la prestación de los servicios esenciales y se responsabiliza con el aseguramiento de las condiciones de vida y las necesidades básicas de la población. A modo de ejemplo, los principios que sostienen el modelo económico cubano al respecto, pautan el grado, extensión e intensidad de la intervención. El texto constitucional preceptúa reglas de intervención, específicas, explícitas y positivas que crean títulos habilitantes en los poderes públicos en relación con la materia económica, o sea, la Constitución se convierte en norma autorizante y legitimadora de acciones que concluyen los entes administrativos y que pueden traducirse en limitaciones para los individuos ${ }^{12}$.

Las Constituciones socialistas en su totalidad, legitiman la intervención del Estado en la economía al concederle al Estado la responsabilidad por el desarrollo económico del país, a partir de promover el crecimiento de la economía y propiciar la redistribución del ingreso. En sus textos se identifican los fines en materia económica, con el propósito de salvaguardar el interés público y garantizar un desarrollo sostenible. Algunas constituciones socialistas pueden fundamentar lo anterior: la Constitución de la URSS de $1936^{13}$, regulaba en su Art. 11, que los fines económicos de la URSS eran aumentar la riqueza social, elevar continuamente el nivel material y cultural de los trabajadores..., En la República Democrática alemana, (RDA) la Constitución de $1968^{14}$, (Art. 2), regulaba como centro de los intereses estatales el aumento del nivel de vida material y cultural del pueblo, sobre la base del desarrollo de la producción socialista, el aumento de la eficacia, el progreso científico-tecnológico y el crecimiento de la productividad.

La Constitución cubana ${ }^{15}$ por su parte, establece como fines estatales en su Art. 16: fortalecer el sistema socialista, satisfacer cada vez mejor las necesidades materiales y culturales de la sociedad y los ciudadanos, promover el

12 Matilla Correa, A., «Constitución y Administración Pública: algunas ideas sobre las bases constitucionales del régimen jurídico-administrativo cubano», en HucK, Winfried y PÉrez Martínez, Yuri, Derecho, Economía y Sociedad en el Siglo XXI, II Simposio Germano-Cubano de Derecho, 2013, La Habana, Cuba, Verlag Dr. Kovač, Hamburg, Alemania, 2013, pp. 319-334.

${ }^{13}$ Constitución de la URSS, 1936, consultado el 5 de julio de 2015 en: https://www. marxists.org/espanol/tematica/histsov/constitucion1936.htm

${ }^{14}$ Constitución de la República Democrática Alemana, promulgada el 8 de abril de 1968. Edición conjunta de la Staatsverlag der Deutschen Demokratischen Republik y la Verlag Zeit im Bild, RDA, 1968.

15 Constitución de la República de Cuba. Asamblea Nacional del Poder Popular, 2005, artículo 16 . 
desenvolvimiento de la persona humana, de su dignidad, el avance y la seguridad del país, para lo cual el Estado organiza, dirige y controla la actividad económica nacional conforme a un plan que debe garantizar el desarrollo programado del país.

De las normas señaladas, se pueden constatar los objetivos generales de la intervención estatal y la propensión de la actividad administrativa directa, fundamentada por el régimen de propiedad imperante y la esencia políticaideológica del Estado socialista.

Podría resumirse este elemento constitutivo de las constituciones económicas socialistas de la siguiente forma: un Estado regulador, planificador y ordenador de la actividad económica, además controlador, en pos de la realización de los principios de justicia social, que se reserva determinados servicios y participa de forma directa como empresario en la actividad económica.

Lo anterior no obsta para que la constitucionalización económica de las bases socialistas deba apostar por un Estado eficiente, cohesionado con la ciudadanía, que transfiera poder hacia las bases de la sociedad, descentralizando y regulando la auto-organización de los trabajadores.

\subsection{La propiedad socialista y sus formas}

En opinión que se ha convertido en referencia obligada en este tema, MARX escribió, «... no cabe pensar en ninguna producción, en ninguna sociedad, donde no exista ninguna forma de propiedad.» ${ }^{16}$ De conformidad con ello, sobre fundamentos marxistas, las Constituciones socialistas colocan a la propiedad estatal como cimiento del sistema económico social, en tanto consideraciones de MARX y ENGELS: «la revolución comunista es la ruptura más radical con las relaciones de propiedad tradicionales, nada de extraño tiene que en el curso de su desarrollo rompa de la manera más radical con las ideas tradicionales» ${ }^{17}$.

La propiedad estatal y las relaciones vinculadas a ella, han constituido el eje fundamental del desarrollo socialista y referente para organizar, articular y dirigir la actividad económica. La propiedad estatal se ha configurado a partir de la comunión de los más importantes medios de producción, los recursos materiales y financieros y las riquezas naturales.

Se reconocen en las distintas constituciones socialistas además, otras formas de propiedad que son distinguidas entre sí, por su objeto.

${ }^{16}$ MarX, C., «De los manuscritos económicos de 1857-1858». MARX, C.; EngELs, F.: Obras completas, tomo 12, p. 714.

${ }_{17}$ Marx, C.; Engels, F., Manifiesto del Partido Comunista. Ed: Política, 1982, La Habana, p. 42. 
En la Constitución de la URSS de $1977^{18}$, la propiedad del Estado fue definida como patrimonio común de todo el pueblo y forma fundamental de la propiedad socialista, caracterizada por el grado más alto de socialización. Gracias al fondo único de la propiedad estatal, se consideraba que era posible que el Estado dirigiera eficazmente el fomento de la economía nacional y aplicar la política económica trazada, expresando los intereses de todo el pueblo. En ese país, al igual que en el resto de los países socialistas, la propiedad socialista surgió principalmente por dos vías: mediante la nacionalización ${ }^{19}$ de la propiedad privada y mediante la cooperativización, de la socialización voluntaria de los instrumentos y medios de trabajo de los campesinos y artesanos, lo que trajo como consecuencia que se reconocieran en la Constitución de ese país, dos formas de propiedad socialista: la propiedad del Estado y la propiedad cooperativa-koljosiana. Ambas formas se caracterizaron por su procedencia - del trabajo- y por la imposibilidad de ser medio de explotación del hombre por el hombre.

La propiedad estatal tiene como peculiaridad, que su disposición o transferencia constituye el contenido patrimonial de las relaciones económicas. Al transferirse de unos organismos económicos a otros, no se transfiere el derecho de propiedad, sino los de administración operativa, manteniendo el Estado su propiedad ${ }^{20}$.

En la URSS la segunda forma de propiedad socialista, provenía de la pequeña propiedad privada que pertenecía antes de la Revolución, a los campesinos y artesanos. Además de los koljoses también eran titulares de ese tipo de propiedad, las sociedades de consumo y las cooperativas de construcción de viviendas, entre otras ${ }^{21}$. Consistía en la propiedad de la comunidad creada mediante la agrupación de ciudadanos en un koljós o cooperativa.

También en la URSS se reconoció la propiedad personal ${ }^{22}$ sobre la base de los ingresos provenientes del trabajo, constituidos por los utensilios de menaje y uso cotidiano, los bienes de consumo y comodidad personal, los

18 SÁnchez Agesta, L., Documentos constitucionales y textos políticos. Ed: Nacional, Madrid, 1982, pp. 149-207.

19 En la década del 50 del pasado siglo surge el principio de «autodeterminación económica» plasmado en la Resolución 626 (VIII) de 21 de diciembre de 1952. Años después, la Asamblea General de la ONU, en su XVIII período de sesiones, aprobó la Resolución 1803, bajo el título «Soberanía Permanente sobre los Recursos Naturales» que amplía y desarrolla el derecho de «autodeterminación económica».

${ }^{20}$ Instituto de Estado y Derecho de la Academia de Ciencias de la URSS: Introducción al Derecho Soviético, Ed: Progreso, Moscú, 1988, p. 186.

${ }^{21}$ Efimov, M., La Constitución de la URSS. Ed: Agencia de Prensa Nóvosti, 1979, Moscú, pp. 44-45.

${ }^{22}$ Artículo 13 de la Constitución de la URSS, de 1977. EfIMOv, Mijail. Ob. cit. p. 45. 
objetos de la hacienda doméstica auxiliar, la vivienda y los ahorros procedentes del trabajo.

En relación con este particular, el elemento común de todas las constituciones socialistas de Europa del Este, consistió en el reconocimiento del papel rector de la propiedad estatal en la economía, regulando otras formas de propiedad que también estructuraban el sistema económico, que no obstante, revelar algunas particularidades, en esencia se parecían mucho: a modo de ejemplo: tanto en la Constitución de la RDA 1968 (Art. 10),como en la Constitución de la República Popular de Bulgaria, de $1971^{23}$, (Art. 14), se reconocieron expresamente como formas de propiedad: la estatal, la cooperativa, la propiedad de las organizaciones sociales y la propiedad personal. En la Constitución de la República Socialista de Rumania, 1965 24 , (Art. 6), se reconoció como propiedad socialista, la propiedad estatal y la propiedad cooperativa, también se garantizó la propiedad de los talleres propios a los artesanos (Art. 11).

A diferencia de los ejemplos anteriores, en la Constitución de la República Socialista Checoslovaca de $1968^{25}$, aunque se establecía que la economía de la República Socialista se desarrollaría sobre la base del sistema económico, en forma planificada y conforme a las condiciones del mercado socialista unitario; (Arts. 4 y 10), no existió mención expresa a las formas de propiedad, sin embargo, del texto pueden inferirse características similares a las constituciones descritas anteriormente.

Reviste particular interés, por sus peculiaridades, la Constitución de la República Federativa de Yugoslavia, de $1963^{26}$, reconocida como «carta de la autogestión $»^{27}$, por las características especiales y contenidos de sus preceptos. De forma atípica en relación con las constituciones socialistas de la época, consagró además de la propiedad social sobre los medios de producción y los medios de trabajo, el trabajo asociado libre, la autogestión y la decisión directa de los trabajadores y de todos los ciudadanos, la libre obtención y reparto autónomo de las ganancias de acuerdo al trabajo. De manera que la propiedad social fue reconocida como un derecho que situaba a todos lo hombre en iguales posibilidades de usarla y gestionarla libremente, en el

${ }^{23}$ Constitución de la República Popular de Bulgaria, aprobada por referéndum el 16 de mayo de 1971, Ed: Sofía-Press, 1971.

${ }^{24}$ Constitución de la República Socialista de Rumania. Ed: Meridiane, Bucarest, 1965.

${ }^{25}$ Ley Constitucional 143/1968 de la Federación Checoslovaca (27 de octubre de 1968).

${ }^{26}$ Constitución de la República Socialista Federativa de Yugoslavia, promulgada el 7 de abril de 1963. Secretaría Federal de Informaciones, Beograd, 1963.

${ }^{27}$ Deleon, Aser, La Constitución Yugoslava. ¿Qué es lo que garantiza, qué obligaciones impone?, Beograd, 1964, p. 10. 
campo de la producción, en la disposición de los frutos del trabajo y en la regulación de las relaciones entre los hombres y sus relaciones recíprocas.

En relación a la forma de propiedad cooperativa, los fundamentos marxistas transitan por la necesaria colectivización de la propiedad en el sistema socialista. Al respecto MARX consideró que: «....si la producción cooperativa (...) ha de sustituir el sistema capitalista; si las sociedades cooperativas unidas han de regular la producción nacional con arreglo a un plan común, tomándolo bajo su control y poniendo fin a la constante anarquía y a las convulsiones periódicas, consecuencias inevitables de la producción capitalista, ¿qué será eso entonces, caballeros, más que comunismo, comunismo realizable? ${ }^{28}$

Se perseguía la constitucionalización de una forma socializada de la propiedad, $-\ll \ldots$...si pudiéramos organizar en cooperativas a toda la población, ya estaríamos con ambos pies en suelo socialista, pues...cuando los medios de producción pertenecen a la sociedad, cuando es un hecho el triunfo de la clase del proletariado sobre la burguesía, el régimen de los cooperadores cultos es el socialismo ${ }^{29}$. Sin embargo, en la práctica se centró la atención en el uso, disfrute y disposición del patrimonio de la cooperativa, en detrimento de sus intrínsecos principios de funcionamiento a lo interno y a lo externo, desvirtuándose de esta forma, a la figura jurídica, sin que se obtuvieran de ella, en todos los casos, los resultados esperados ${ }^{30}$.

En la experiencia socialista posterior a LENIN, el cooperativismo fue asumido en su sentido estrecho, como instrumento de socialización de la economía privada individual campesina y urbana. El socialismo de base cooperativa preconizado por Lenin no negaba, sino presuponía un Estado proletario fuerte que concentrara la propiedad social sobre los medios fundamentales de producción, pero explotados por colectivos laborales en posesión colectiva ${ }^{31}$.

Como otra forma de propiedad, la propiedad personal se defendió teórica y jurídicamente en el constitucionalismo socialista, en oposición a la propiedad privada que genera capital sobre la base del trabajo ajeno, de la explotación del hombre por el hombre. «El derecho de propiedad personal del ciudadano soviético - sostuvo JÁLFINA- es su derecho de poseer, utilizar y disponer

28 Marx, Carlos, La guerra civil en Francia, en http://www.marxist.org/ espanol/m-e/1870s/gcfran/guer.htm, consultado en septiembre de 2010.

${ }^{29}$ LenIn, Vladimir I., Sobre la cooperación, en Obras escogidas en tres tomos, t.3, Ed: Progreso, Moscú, 1961, p. 778, 784 y 781.

30 Rodríguez Musa, Orestes, La cooperativa como figura jurídica. Perspectivas constitucionales en Cuba para su aprovechamiento en otros sectores de la economía nacional diferente al agropecuario. Ed: Dykinson. S.L. Madrid, 2012, p. 48.

${ }^{31}$ Figueroa Albelo, Víctor, Economía Política de la transición al socialismo. Experiencia cubana. Ed: Ciencias Sociales, La Habana, 2009, p. 171. 
de los bienes otorgados a él, como consecuencia de la distribución del producto social - principalmente en calidad de distribución según el trabajopara satisfacer sus necesidades materiales y culturales»" " $^{32}$ "Así pues, el derecho de propiedad personal surge como resultado de la distribución organizada por la sociedad, de los artículos de la producción social y encarna una de las formas de satisfacción de las necesidades individuales» ${ }^{33}$.

En el socialismo pueden convivir armónicamente, la propiedad estatal y la propiedad privada, el reconocimiento constitucional pasado y presente, la urgencia de los reacomodos tácticos socialistas y las nuevas condiciones en las que construyen este tipo de sociedades, lo constatan. El predominio de la propiedad privada supone el predominio del capital sobre el trabajo y el predominio del mercado sobre la sociedad. En consecuencia, en una sociedad socialista, lo primero y fundamental que debe quedar resuelto constitucionalmente es el predominio de la propiedad socialista y el establecimiento de regulaciones y límites a la propiedad privada.

\subsection{La planificación de la economía}

Otro elemento importante que caracteriza los fundamentos económicos constitucionales socialistas, es la realización de la dirección económica sobre la base de planes estatales para el desarrollo económico y social, que conjugan el principio territorial y de ramas económicas, así como la dirección centralizada, con la independencia administrativa e iniciativas propias de las empresas y otras agrupaciones. La planificación es un instrumento regulatorio de las relaciones en la esfera de la economía.

La planificación es concebida como el eslabón central de la gestión económica de la sociedad socialista. Comprende la elaboración de diferentes planes de la economía nacional, de distintas ramas, empresas y también de los territorios en los distintos niveles. Al respecto, señalaba Carlos Rafael RODRÍGUEZ, que «no es una mera operación técnica, a pesar de su contenido económico: es ante todo una operación política. Detrás de cada acto de planificación hay una filosofía social, una proyección socioeconómica de carácter histórico» ${ }^{34}$.

En el socialismo los intereses empresariales se subordinan a objetivos más generales. De este modo, la función de la planificación socialista es armonizar la actividad económica en beneficio de la sociedad en su conjunto,

32 JÁlfinA, R., El derecho de propiedad del Estado en la URSS, Ed. Progreso, Moscú, 1981, p. 7.

33 Ídem.

${ }^{34}$ Rodríguez, C. R., Problemas prácticos de la planificación centralizada. Revista Comercio Exterior, México, Vol. 30, n. ${ }^{\circ}$ 11, Noviembre 1980, p. 1215. 
por ello, autores soviéticos reconocían que «la planificación del Estado, científicamente fundamentado, asegura en el grado máximo: primero, la acertada coordinación en el desarrollo de todas las ramas de la economía nacional del país; segundo, el constante progreso técnico de la sociedad; tercero, la distribución racional de las fuerzas productivas y el aumento de la productividad del trabajo; cuarto, la elevación del bienestar de los trabajadores $\rangle^{35}$.

La planificación es un proceso complejo, dinámico, emancipatorio, a través del cual se fijan los indicadores de la actividad económica, constituye una forma de dirección de la economía, para un período de tiempo determinado, orientado en beneficio de la sociedad, como construcción colectiva desde los colectivos laborales, y las diferentes comunidades.

La planificación es esencialmente una cuestión de intereses, no debe identificarse con una técnica determinada. Constituye, ni más ni menos, una expresión de la forma en que se distribuye el poder económico y político en una sociedad. Precisamente por ello, afirmó el Che que la planificación era el modo de ser y de desarrollarse la sociedad socialista; lo que él llamaba su categoría definitoria, sin la cual no existiría el socialismo ${ }^{36}$.

De esta forma los mecanismos de la producción social, como formas a través de la cual se lleva a cabo la planificación, se erigen como rasgos característicos del modelo, donde lo óptimo se presenta a partir de la interrelación de instrumentos directos (designación de tareas y asignación de recursos, que deben someterse a un plan y a normas previamente definidas) e instrumentos indirectos (conducen el mercado a través de políticas fiscales, monetarias, etc. incentivando o desestimulando el actuar de los distintos agentes económicos).

Las Constituciones socialistas europeas reconocieron el papel de la planificación, de forma muy similar, veamos algunos ejemplos: En la Constitución de la República Democrática Alemana de 1968, el sistema económico vinculaba la planificación y la dirección central de los aspectos básicos del desarrollo social por el Estado, a la responsabilidad individual de los productores socialistas y de los órganos estatales locales (Art. 9). La Constitución búlgara de 1871 estableció que el Estado dirigía la economía nacional y los demás sectores de la vida social de acuerdo con los planes únicos de desarrollo social-económico, apoyándose en el desarrollo de esta actividad en las iniciativas y labor creadora de los colectivos de trabajadores, de los institutos científicos y de las organizaciones sociales (Art. 22). En la República Socialista de Rumanía, se estableció constitucionalmente que toda la actividad del

35 Denisov, A.; Kirichenko, M., Derecho Constitucional soviético. Ediciones de lenguas extranjeras, Moscú, s/f. p. 122.

${ }^{36}$ GonzÁlez GutiÉRrez, A., La planificación en la brecha. Cuba: Investigación Económica, n. ${ }^{\circ}$ 1. Enero-Marzo 2002, p. 3. 
Estado, tenía como fin el desarrollo de la sociedad... para esto, «organiza, planifica y dirige la economía nacional...» (Art. 13).

En el caso cubano, el plan de desarrollo económico constituye la principal herramienta macroeconómica, en un contexto en el que el funcionamiento de la economía, se caracteriza por la utilización de las relaciones monetario-mercantiles y los mercados. La consideración de que ello es posible es el fundamento del camino socialista. «Esa capacidad debe ser vista como un complejo de acciones combinadas: regulaciones jurídicas, económicas, organizativas, ideológicas, políticas, culturales, comunicacionales. No se trata solamente de una justa y proporcionada política impositiva sobre todo tipo de actividad económica, sino de la integración de acciones en una misma dirección: regular el mercado, con la fortaleza fundamental del predominio de la propiedad social sobre los medios fundamentales de producción de bienes y servicios ${ }^{37}$.

Aunque la planificación se erige como mecanismo de dirección económica en el socialismo, pueden encontrarse actividades de este tipo en el capitalismo, sobre todo en modelos con mayor intervención del Estado en la economía, de igual modo en el sistema socialista no se excluyen las contradicciones que se presentan con la convivencia de plan y mercado, donde «el mercado es un conjunto de relaciones económicas vinculadas con la realización de las mercancías, con el paso de las mismas desde los productores hasta los consumidores; un cambio mercantil organizado planificadamente, en interés del desarrollo proporcional de la economía nacional y de una satisfacción más plena de las necesidades sociales $»^{38}$ y puede contribuir al logro de una adecuada correspondencia entre las necesidades sociales y los recursos productivos, así como, servir de instrumento para coordinar la actividad económica de las empresas con las exigencias del Estado y de la población cuando se realiza de forma planificada.

Los debates sobre este tema están estrechamente relacionados con la adopción de modelos y los niveles de centralización y descentralización que deben considerarse idóneos ${ }^{39}$.

${ }^{37}$ Machado Rodríguez, D., Equidad, igualdad e igualitarismo: A propósito del VII congreso del PCC. http://api.ning.com:80/files/bGawF3RRkaeyZmyhdO7MaKftWIP8cacolNdptBhvnyzyEE8nMu2avaEdmylFiJXn7cNfB-MknvEyspo 7ycGZ3*ngmtfgNZAi/ RCBaez_Cubaloquevadeayerahoy.JPG?width=560<http://api.ning.com/files/bGawF3RRkaeyZmyhdO7MaKftWIP8cacolNdptBhvnyzyEE8nMu2avaEdmylFiJXn7cNfBMknvEyspo7ycGZ3*ngmtfgNZAi/RCBaez_Cubaloquevadeayerahoy.JPG, consultado en agosto de 2015.

${ }_{38}$ BaChurin A. V., Métodos de dirección de la economía planificada, Ed: Ciencias Sociales, La Habana, 1979, pp. 193-194.

39 Odriozola Guitart, J., «Plan y mercado: reflexiones sobre un debate no zanjado», en Cobo Roura, Narcizo et al. Temas de Derecho Económico, Ed: Félix Varela, La Habana, 2007, pp. 60-83. 


\subsection{La administración operativa de los bienes}

Como resultado del reconocimiento de la propiedad socialista (estatal en varias constituciones), como propiedad fundamental, y de la gestión de la misma casi de forma exclusiva por el Estado, se deriva la concepción de la administración estatal de la economía y la participación directa del Estado en la misma. La economía queda conformada constitucionalmente como un conjunto único, integrado por la producción social, la distribución y el intercambio, organizada conforme al principio de centralismo democrático, principio que se formula normativamente a partir de la combinación entre la dirección centralizada de la gestión económica y la iniciativa y autonomía de los eslabones de la base, a partir de la responsabilidad de los órganos y funcionarios estatales por las tareas encomendadas.

La Constitución de la URSS (1977), en su artículo tercero establecía que la organización y la actividad del Estado soviético se estructuraba centralizadamente; de la siguiente forma: electividad de todos los órganos de poder estatal de abajo arriba, deber de rendir cuentas al pueblo de su gestión, y obligatoriedad de las decisiones de los órganos superiores para los inferiores; subrayaba la importancia de la autogestión financiera para el desarrollo de la economía.

Como contenido esencial de la administración operativa de los bienes, el eslabón básico de producción a priorizar en el sistema de gestión de la economía nacional, es la empresa; regularidad objetiva de la economía socialista. La idea defendida al respecto por constitucionalistas y economistas, puede resumirse de la siguiente forma: «Indistintamente del número de eslabones y subsistemas que contenga el sistema de gestión de la producción, se prioriza como cualitativamente distinto a los demás a la empresa, eslabón donde se crean directamente los valores materiales, se prestan los servicios y donde el productor está vinculado con el consumidor, todo ello, sobre la base del resultado final del trabajo, que pasa a la esfera de la distribución y el intercambio ${ }^{40}$.

Las empresas y organizaciones utilizan directamente los bienes públicos bajo determinados derechos y deberes, en correspondencia con el lugar que ocupan en el sistema de la producción social. En particular el derecho de administración operativa incluye la facultad de poseer, usar y disponer de los bienes adscritos a las empresas y organizaciones en los términos que señala la ley. De la misma forma, se establece en la ley el contenido del derecho de administración operativa y las características esenciales del marco, dentro del cual se ejerce el mismo.

${ }^{40}$ Instituto de Estado y Derecho de la Academia de Ciencias de la URSS. Ob. cit, p. 158 . 
No obstante lo dicho, una de las formas jurídicas que expresan la compleja estructura de la propiedad del Estado socialista, es la separación de la responsabilidad del Estado y las empresas y organizaciones estatales, las que deben responder independientemente de sus obligaciones. En ese sentido, de conjunto con el estatuto de aprobación, el balance de la persona jurídica constituye un documento para definir la situación patrimonial y los resultados financieros de su actividad. El Estado obra como sujeto inmediato en esferas muy reducidas de relaciones de propiedad. La realización de los derechos y obligaciones en las relaciones de propiedad concierne a órganos que actúan en representación del Estado ${ }^{41}$.

A modo de ejemplo, en la ley constitucional de la Federación Checoslovaca, se establecían las competencias específicas del Estado según el ámbito concreto de las relaciones. En el caso de las empresas socialistas, la República tenía competencia para la regulación de las relaciones jurídicas, el procedimiento de las organizaciones económicas, los principios de la regulación de las Empresa cooperativas y menores; la regulación de las relaciones económicas entre las organizaciones socialistas; la regulación de la protección de la producción y del comercio, así como, de la participación de los consumidores, y en especial de la regulación de los derechos industriales, de la normalización, de la supervisión estatal y de la inspección estatal; así como, de los principios de la producción y de la explotación de la riqueza minera, (Art. 24).

Por su parte, la Constitución de la República Popular de Bulgaria, establecía en su artículo 17, la creación por el Estado de organizaciones económicas y de otros tipos, en ejercicio de su derecho de propiedad, y su participación en empresas estatal-cooperativas, a las que confiaba bienes para que los administraran, De igual manera el Estado podía en virtud de la normativa constitucional, conceder determinados bienes de su propiedad en concepto de usufructo a organizaciones cooperativas y sociales, así como a ciudadanos.

En ese contexto, la empresa estatal no pertenece a la colectividad de los trabajadores involucrados con la misma, sino a toda la sociedad, salvo algunas diferencias de la regulación constitucional yugoslava, que como se planteó, se mantuvo la misma concepción acerca de la propiedad, pero con peculiaridades importantes en torno al derecho de autogestión de los trabajadores a decidir acerca del ingreso económico de las empresas, en correspondencia con el trabajo y las obligaciones de las empresas con la comunidad social, sobre la base de que las libertades y la posición de los hombres dependían precisamente de ello.

41 JÁlfinA, Raísa: Ob. cit. pp. 55-62. 


\subsection{Los derechos socioeconómicos y las políticas públicas}

Como consecuencia de relaciones jurídicas existentes entre los individuos y el Estado, es deber jurídico fundamental de este último, garantizar el pleno ejercicio y disfrute de los derechos del titular de la soberanía.

En Cuba, del análisis del primer artículo constitucional se infiere la obligatoriedad estatal de reconocer y garantizar los derechos individuales y sociales, toda vez que establece el mencionado artículo que el Estado se organiza para el disfrute de la libertad política, la justicia social y el bienestar individual y colectivo.

En cualquier país, la inclusión de los derechos en el texto constitucional ha de ser expresión del alcance soberano y resultado de conquistas democráticas. Por consiguiente, el ejercicio real de los derechos y su protección pueden considerarse directamente proporcionales a la legitimación del aparato estatal, en relación con derechos y deberes de sujetos jurídicos que, en plano de igualdad jurídica, tributan activamente al logro del consenso y estabilidad política de una sociedad.

Los contenidos económicos de la Constitución deben vincular el proyecto económico, las políticas económicas sociales y las disposiciones orgánicas en relación con las mismas. En ese sentido, las políticas públicas como formas de actuación de los poderes públicos que penetran en las relaciones económicas de producción y en las necesidades sociales, construyendo los grandes servicios públicos y organizando la economía, constituyen garantías materiales del ejercicio de los derechos ciudadanos.

En el caso particular que nos ocupa, los derechos socioeconómicos y culturales, con más fuerza que otros, requieren precisamente de las prestaciones positivas que debe brindar el Estado para garantizar trabajo digno, facilitar la salud, brindar educación, proteger y desarrollar el arte y la cultura, entre otros, generando obligaciones estatales de resultados y de conducta, para lo que cual se requiere una distribución de los recursos de forma equitativa.

Lo anterior se convierte en factor determinante del diseño constitucional de la economía socialista, vinculada al predominio de la propiedad estatal sobre otras formas de propiedad, en tanto, la distribución de los ingresos se debe corresponder con la calidad, cantidad y resultados del trabajo, a la vez que se garantice por parte del Estado, la seguridad social, la asistencia social y la protección, seguridad e higiene del trabajo, si se tiene en consideración que la satisfacción de los intereses materiales y espirituales de los individuos es junto a la propiedad socialista y la planificación de la economía, elementos constitutivos del modelo socialista.

De manera que este tipo de constituciones, por la esencia de la finalidad estatal que consagran, regulan la prevalencia en el modelo económico de las formas socialistas de distribución, a la vez que reconocen la responsabilidad 
estatal en la garantía de la prestación de los servicios o la supervisión y control de los mismos, según sea el caso.

Uno de los derechos sociales que mejor ilustra el planteamiento anterior, es el derecho al trabajo. Veámoslo a partir de la regulación de la Constitución cubana de 1976, donde es regulado con una triple connotación: como derecho, como deber y como motivo de honor, en compañía del derecho al descanso retribuido, garantizado por la jornada laboral de 8 horas, el descanso semanal y las vacaciones anuales pagadas, la protección adecuada a todo trabajador impedido por su edad, invalidez o enfermedad, así como a la familia, en caso de muerte del trabajador, mediante el sistema de Seguridad Social. De la misma forma, se garantiza la protección e higiene del trabajo, mediante la adopción de medidas adecuadas para la prevención de accidentes $\mathrm{y}$ enfermedades profesionales.

Con el objetivo de consolidar y perfeccionar las regulaciones que garantizan la protección de los derechos y el cumplimiento de los deberes, derivados de la relación jurídico-laboral establecida entre los trabajadores y los empleadores, fortalecer los mecanismos para exigir una mayor disciplina y reafirmar la autoridad y responsabilidad de la administración, se promulgó la Ley n. ${ }^{\circ} 116$, Código de Trabajo que regula como principios fundamentales que rigen el derecho al trabajo, los siguientes: el trabajo es un derecho y un deber social del ciudadano, la igualdad en el trabajo; todo ciudadano en condiciones de trabajar tiene derecho a obtener un empleo atendiendo a las exigencias de la economía y a su elección, tanto en el sector estatal como no estatal; sin discriminación por el color de la piel, género, creencias religiosas, orientación sexual, origen territorial, discapacidad y cualquier otra distinción lesiva a la dignidad humana; igualdad en el salario; el trabajo se remunera sin discriminación de ningún tipo en correspondencia con los productos y servicios que genera, su calidad y el tiempo real trabajado, donde debe regir el principio de distribución socialista de cada cual según su capacidad a cada cual según su trabajo,

prohibición del trabajo infantil y la protección especial a los jóvenes que se incorporan al trabajo, con el fin de garantizar su desarrollo integral; el derecho de los trabajadores a la capacitación y superación, en las condiciones específicas que establece la legislación; el derecho de los trabajadores al descanso diario, semanal y de las vacaciones anuales pagadas; el derecho de los trabajadores a la seguridad y salud en el trabajo mediante la adopción de medidas para la prevención de accidentes de trabajo y enfermedades profesionales; el derecho de los trabajadores y sus familias a recibir la protección de la seguridad social de acuerdo con lo establecido en la legislación vigente; los derechos de trabajo y de seguridad social que se confieren a la trabajadora, para proteger su maternidad y facilitar su atención médica, el descanso pre y post natal y el cuidado de los hijos menores; el derecho de los trabajadores 
a asociarse voluntariamente y constituir organizaciones sindicales, de conformidad con los principios unitarios fundacionales, sus estatutos y reglamentos que aprueban democráticamente; y actúan con apego a la ley y el derecho de los trabajadores a promover acciones ante los órganos, autoridades e instancias competentes, para el reconocimiento y cumplimiento de los derechos de trabajo y de seguridad social consagrados en la legislación.

La obligación del Estado entraña entonces el reconocimiento legal de los derechos, así como, la creación de garantías materiales y jurídicas que permitan el real ejercicio de los mismos.

\section{EL MODELO SOCIALISTA DE EUROPA DEL ESTE. UN BREVE REPASO A ALGUNAS CAUSAS ECONÓMICAS DE SU DERRUMBE}

Precisamente, en la misma medida que los fundamentos económicos analizados, le dan contenido y realización concreta al sistema socialista, su disfuncionalidad sistémica, unido a otros múltiples factores de diversa índole, bajo paradigmas dialécticos marxistas, incidieron en el derrumbe del modelo europeo.

Teniendo en cuenta la profundidad insuperable de su análisis sobre este tema, hemos tomado como guía y sistematizado ideas esenciales del profesor Julio Fernández Bultét2 para ofrecer algunas causas económicas del derrumbe del sistema socialista europeo, a saber:

La economía socialista evidenció enormes incapacidades para afrontar el desafío de igualar o superar a la economía capitalista. El llamado socialismo real procuró competir con el capitalismo ofreciendo a los hombres los mismos valores y hasta los mismos resultados del capitalismo, pretendiendo que además fueran para todos. Es socialismo se visualizó como el arte de socializar para todos la posibilidad de acceso a una vida burguesa y eso no es posible ni en el capitalismo, ni en el socialismo, para todos.

Aunque lograr la propiedad social sobre los medios fundamentales de producción, requería de una previa estatalización de esa propiedad; se confundió en la realización práctica socialista, socialización con estatalización. No se alcanzó la sustitución de la propiedad privada capitalista, por la propiedad social, como fue concebido por los clásicos del marxismo.

Existió una altísima centralización burocrática de la disposición sobre la propiedad socialista, en conjunción, con otro fenómeno, evidentemente contradictorio, a partir del cual existía un sentimiento popular de no-propiedad,

${ }^{42}$ Fernández Bulté, J., Teoría del Estado y del Derecho. Tomo I. Ed: Félix Varela, La Habana, 2001, pp. 169-184. 
o de que nada es propiedad de nadie, que produjo una fuerte alienación de las masas en su relación con la propiedad estatal.

Como elementos concurrentes se dio una planificación altamente centralizada y burocrática y la ineficiencia en el aparato de gestión, que no obtenía intereses directos en el resultado de la producción.

Se evidenció falta de mecanismos de estimulación que sirvieran de palanca, micro y macroeconómica, a la producción y a los servicios.

Estas inconsecuencias del modelo económico no pueden desligarse de su unidad dialéctica con su manifestación política, es decir, con la forma en que se organizó ese Estado que debía propender -después de ser el propietario de los medios fundamentales de producción- a que esa propiedad se convirtiera en propiedad social de todo el pueblo.

La situación de hostigamiento y bloqueo que tuvieron que enfrentar, producto entre otros factores, de la guerra fría, obligaron a la centralización y fortalecimiento del Estado y con ello a que se anularan en gran medida, las iniciativas y la capacidad de autenticidad política de grandes sectores de la sociedad civil. No hubo verdadera participación y se creó un divorcio entre la dirección política y estatal y las masas. No se vertebraron las esenciales libertades individuales, las aspiraciones subjetivas de la ciudadanía, ni se engarzaron coherentemente con un proyecto social absorbente.

De los elementos anteriores, puede deducirse, que el socialismo científico tal cual lo postularon los clásicos del marxismo, nunca ha sido refutado, ni fracasó en Europa del este. Es evidente que allí en el socialismo real, naufragó una adulteración del ideario del marxismo.

De hecho el discurso podría ser totalmente contrario: los adelantos, logros y conquistas sorprendentes de los países socialistas de Europa del este, se alcanzaron casi a pesar del modelo exclusivamente económico, apoyándose en otras cualidades del sistema, como sus fundamentos políticos, éticos y la formación de nuevos valores morales, pero no precisamente en los propios resortes económicos constitucionalizados.

ENGELS, lo había analizado: «El desarrollo político, jurídico, filosófico, religioso, literario, artístico, etc., descansa en el desarrollo económico. Pero todos ellos repercuten también los unos sobre los otros y sobre su base económica. No es que la situación económica sea la causa, lo único activo, y todo lo demás, efectos puramente pasivos. Hay un juego de acciones y reacciones, sobre la base de la necesidad económica, que se impone siempre, en última instancia $)^{43}$.

43 Engels, F., Carta a W. Borgius en Breslau, de 25 de enero de 1894, Revista Der Sozialistische Akademiker, Obras escogidas, tomo III, Ed. Progreso, Moscú, 1980, p. 284. De igual forma, la carta de Engels a J. Bloch, Obras escogidas en dos tomos, tomo II, Ed. Progreso, Moscú, 1971, p. 490. 
Evidentemente, se hizo depender la construcción socialista, de la realización económica y se minimizó la importancia de los seres humanos y la creación de instituciones y mecanismos que le permitieran al ciudadano auto transformarse.

\section{PARTICULARIDADES DE LA REGULACIÓN CONSTITUCIONAL DE LA ECONOMÍA EN LA REPÚBLICA SOCIALISTA DE VIETNAM}

Al comparar los textos constitucionales vietnamitas de $1959^{44}$ y de $1992^{45}$, puede apreciarse dentro de marcos socialistas expresamente declarados, un replanteamiento de los contenidos económicos de la Constitución en el último de ellos, que acentúan el carácter atípico de los postulados constitucionales en relación con el resto de las constituciones socialistas de Europa del Este.

No obstante, la propiedad estatal de todo el pueblo o propiedad estatal desempeñar el papel dirigente en la economía, desde la promulgación del texto de 1959, convivieron esta forma de propiedad y los intereses colectivos de las masas trabajadoras, con formas privadas de propiedad de los medios de producción, lo mismo por parte de artesanos y otros trabajadores individuales, que de capitalistas nacionales reconocidos expresamente, siempre que esta forma de propiedad no fuera usada para desorganizar la vida económica de la nación o para sabotear los planes económicos del Estado.

En la Constitución de 1992, el Estado promueve una economía mercantil bajo la administración del Estado y siguiendo una orientación socialista, con la liberación de todo el potencial productivo, el desarrollo de todas las posibilidades latentes de todos los componentes de la economía -el sector estatal, el sector colectivo, el sector privado individual, el sector capitalista privado y el sector capitalista del Estado en diversas formas- empujando con la construcción de las bases materiales y técnicas, la ampliación de la cooperación económica, científica, técnica, las relaciones con los mercados mundiales. (Art.15 y 16).Mientras el Estado ejerce la gestión única de las tierras, de acuerdo con la planificación física y las leyes, asegurando su uso justo y eficaz, (Art. 18).

Se promueve la economía familiar y la economía colectiva a expensas de los recursos financieros y físicos de los ciudadanos, destinados a la coopera-

${ }^{44}$ Constitución de la República Democrática de Viet-Nam, 31 de diciembre de 1959, $\mathrm{s} / \mathrm{e}, \mathrm{s} / \mathrm{f}, \mathrm{s} / \mathrm{l}$.

${ }_{45}$ Constitución de Viet-Nam, 1992. http://www.wipo.int/wipolex/es/text.jsp?file id=183902 Organización Mundial de la Propiedad Intelectual (WIPO), consultado el día 5 de julio de 2015 . 
ción de la producción y a operaciones comerciales, las que son promovidas para su desarrollo. El Estado facilita la consolidación y ampliación de las cooperativas eficientes.

No existen límites para que los sectores capitalistas individuales y privados, puedan seleccionar su forma de producción y comercialización y crear empresas en las ramas y profesiones beneficiosas para la vida económica del país. (Art. 21).

Resulta de trascendental interés que los ciudadanos puedan participar de forma directa como propietarios, en los asuntos del Estado y se regule expresamente la responsabilidad ciudadana en la protección de los bienes colectivos, derechos e intereses legítimos, en la preservación de la seguridad nacional, el orden y la seguridad social, y en la organización de la vida comunitaria.

Un programa sistemático de reforma económica, que se inició en 1986 y que se conoció con el nombre de doimoi ('Renovación Vietnamita'), impulsó la competencia, la apertura del mercado y la inversión extranjera, con el objetivo de restablecer la prosperidad económica y de emular a las economías con fuerte crecimiento de Asia. Vietnam se ha convertido en la segunda economía de más rápido crecimiento de Asia después de China, con una media del $6,9 \%$ de alza en el último quinquenio ${ }^{46}$.

\section{CARACTERÍSTICAS CONSTITUCIONALES ESENCIALES DEL MODELO ECONÓMICO ${ }^{47}$ CUBANO}

La Constitución cubana regula los contenidos correspondientes a la constitución económica de manera difusa ${ }^{48}$ : Se incluyen en algunos artículos dispersos por el texto, principalmente como parte del capítulo I, sobre los

${ }^{46}$ PIB de Vietnam 2015 consultado el 2 de julio de 2015 www.datosmacro.com/pib/ vietnam.

${ }^{47}$ En su aplicación al campo de la economía, un modelo es «una construcción del pensamiento que ilustra de manera simplificada el funcionamiento o el desarrollo de la economía nacional o de una parte de esta». DREWNOWSKI, J., Pequeño diccionario económico, Polgos, Varsovia, 1958. «El término de modelo económico se emplea para expresar de forma sintética los principios, el modo de funcionamiento y los mecanismos de gestión de un sistema económico. Así, por ejemplo, se habla de capitalismo de libre competencia, o de capitalismo monopólico; de planificación material centralizada, etc.».GONZÁlez GutiéRrez, A., Plan y mercado aspectos estratégicos en el perfeccionamiento del modelo de planificación. Cuba: Investigación Económica n. ${ }^{\circ} 3$ Julio - Septiembre 2000 , p. 3.

${ }^{48}$ Las constituciones revolucionarias de América Latina con vocación social, le destinan un espacio específico a los contenidos económicos. (Capítulo IV, Soberanía económica, Constitución de la República de Ecuador, 20 de octubre de 2008); (Título VIm Del Sistema Socioeconómico, Constitución de la República Bolivariana de Venezuela, 1999). 
«Fundamentos políticos, sociales y económicos del Estado», así como, en el Preámbulo, donde se regulan algunos elementos esenciales que fundamentan el proyecto económico del Estado.

En Cuba el proyecto económico constitucionalmente trazado, es la comunión de aspectos políticos e ideológicos. La Constitución otorga los límites fronterizos al marco de actuación y define los principios para la concreción de los objetivos del socialismo y del sistema político y social revolucionario establecido en la Constitución, con el propósito de garantizar su sostenibilidad. Este elemento le concede cierta rigidez al sistema económico, en tanto el socialismo que es su plataforma, a partir de la reforma constitucional del año 2002 resultó consagrado como irrevocable. De manera, que sus posibles modificaciones estarán condicionadas a la expresión del contenido específico atribuible al socialismo mismo.

El texto constitucional regula reglas de intervención específicas, autoriza y legitima acciones de los entes administrativos, que pueden traducirse en limitaciones para los individuos, cuestión que constituye expresión inmediata de todos los valores que fundamentan al régimen desde una perspectiva iusfilosófica ${ }^{49}$.

A diferencia de otros modelos constitucionales, la Constitución cubana después de la reforma constitucional del año 1992, posibilita el desarrollo de actividades privadas para que actores no estatales, sean colectivos o individuales, ejerzan la iniciativa económica sobre la base de los fundamentos marxistas de la propiedad individual y de los principios del sistema político socialista, sustentado en el principio de complementariedad: el Estado mantiene su rol de actor principal de la economía, traza los postulados y estrategias en su conducción, encauza las acciones de todos al cumplimiento de sus objetivos en aras de garantizar el bienestar común; en armonía con otros sujetos quienes, con su participación en la gestión económica, deben colaborar en imprimirle mayor eficiencia y eficacia al socialismo.

El régimen económico resulta específicamente asentado a partir de los principios y valores que consagra el artículo 1 constitucional ${ }^{50}$, ya mencionado, al establecer que el Estado es socialista y prescribir como sus objetivos, el disfrute de la libertad política, la justicia social, el bienestar individual y colectivo y la solidaridad humana. Con la misma delineación principista la Constitución consagra el sistema de economía basado en la propiedad socialista de todo el pueblo sobre los medios fundamentales de producción, la

49 Pérez Martínez, Y., Fundamentos jurídicos para la armonización de intereses públicos y privados en sede de alojamiento turístico en cuba. La Habana, 2014, p. 93.

${ }^{50}$ Constitución de la República de Cuba de 1976, Gaceta Oficial de la República de Cuba, Edición Especial No. 2, de 24 de febrero de 1976. Ley de Reforma Constitucional, de 12 de julio de 1992, Gaceta Oficial de la República No.6, de 13 de julio de 1992. 
distribución socialista «de cada cual según su capacidad, a cada cual según su trabajo», la supresión de la explotación del hombre por el hombre, así como, la regulación de supremacía del interés público frente al interés privado en las relaciones económicas.

Sobre la base de una orientación ideológica definida, la Constitución promueve la intervención del Estado en la economía con carácter regulador, planificador y controlador de la actividad económica, reservándose la prestación de determinados servicios y los principales instrumentos de fomento para impulsar el desarrollo del país. La enumeración de los bienes que conforman el patrimonio público (Art. 15) constituye, entre otras, un reflejo de la proyección intervencionista del Estado en la actividad económica, con el objetivo de garantizar las condiciones que propicien la realización del principio de igualdad (Art. 44) y promover el desenvolvimiento de la persona humana y de su dignidad, el avance y la seguridad del país (Art. 16).

Por definición constitucional, el Estado administra directamente los bienes que integran la propiedad socialista de todo el pueblo y puede crear y organizar empresas y entidades encargadas de su administración, cuya estructura, atribuciones, funciones y el régimen de sus relaciones son regulados por normas infraconstitucionales. (Art. 17).

La Constitución le atribuye al Estado la función de organizar, dirigir y controlar la actividad económica nacional conforme a un plan que garantice el desarrollo programado del país, a fin de fortalecer el sistema socialista, satisfacer cada vez mejor las necesidades materiales y culturales de la sociedad y los ciudadanos, promover el desenvolvimiento de la persona humana y de su dignidad, el avance y la seguridad del país; administrar directamente los bienes que integran la propiedad socialista de todo el pueblo; o crear y organizar empresas y entidades encargadas de su administración, cuya estructura, atribuciones, funciones y el régimen de sus relaciones son regulados por la ley, así como, dirigir y controlar el comercio exterior (Arts. 16, 17 y 18c).

La Constitución cubana reguló varias instituciones inspiradas en los postulados reconocidos por otras constituciones socialistas, de todas, fue la propiedad una de las que recibió mayor influencia. Constitucionalmente la propiedad es reconocida como parte integrante de los fundamentos políticos, sociales y económicos. No se regula expresamente como derecho, aunque, en algunas de las modalidades reguladas, es ineludible inferir esa condición.

Se reconocen en la Constitución, de forma expresa, seis formas de propiedad además de la propiedad estatal socialista; la propiedad de los agricultores pequeños sobre las tierras que legalmente les pertenecen y los demás bienes inmuebles y muebles que les resulten necesarios para la explotación a que se dedican, la propiedad de las cooperativas de producción agropecuaria, la propiedad personal sobre los ingresos y ahorros procedentes del trabajo propio, sobre la vivienda que se posea con justo título de dominio y los demás 
bienes y objetos que sirven para la satisfacción de las necesidades materiales y culturales de la persona, la propiedad de las empresas mixtas, sociedades y asociaciones económicas que se constituyen conforme a la ley y la propiedad de las organizaciones políticas, de masas y sociales sobre los bienes destinados al cumplimiento de sus fines.

Se destaca la propiedad estatal socialista, regulada en el Art. 14 constitucional que le confiere la plataforma socialista al régimen socio-económico cubano. Está conformada por los bienes colectivos que integran el patrimonio del Estado para garantizarlos intereses primordiales de la comunidad en su conjunto. Por su carácter colectivo y socializador pueden ser reconocidas también como propiedad de contenido socialista, los tipos de propiedad regulados como, propiedad de las organizaciones políticas, de masas y sociales y propiedad cooperativa.

Las organizaciones políticas, de masas y sociales son consideradas sujetos de relaciones jurídicas y en ese sentido, poseen patrimonio propio, determinado éste por los estatutos o reglamentos que establecen los fines que se proponen y que se cumplimentan con sus bienes, únicos sobre los que tienen el derecho de propiedad.

Por su parte, la propiedad cooperativa recae sobre los bienes que sus miembros aportan, constituye una forma de colectivización que destina su producción no sólo al beneficio de los cooperativistas, sino también al desarrollo de la producción. En la constitución esta forma de propiedad quedó reservada de forma exclusiva a la cooperativización agrícola, imposibilitando que esta forma asociativa expandiera todas sus posibilidades en la vida social del país. En la actualidad sin reconocimiento constitucional aun, se regula para distintas modalidades, por otras disposiciones normativas ${ }^{51}$ como una forma avanzada y eficiente de producción socialista.

En la regulación del artículo 21 de la Constitución cubana confluyen la concepción soviética de la propiedad personal, reducida al ámbito del consumo, y la noción marxista de propiedad individual sobre los medios e instrumentos de trabajo personal o familiar, vinculado a la producción o la prestación de servicios.

La Constitución cubana de 1976 proscribió la propiedad privada sobre los medios de producción, excepto los poseídos por los pequeños agricultores y un sector de transportistas individuales. Con la reforma de 1992, sin reconocimiento expreso, la propiedad privada individual sobre medios de producción, recibe un reconocimiento elíptico ${ }^{52}$ en el artículo $15 \mathrm{al}$ admitirse, en el

${ }^{51}$ Decreto Ley n. $^{\text {o }} 305$ del Consejo de Estado, de 15 de noviembre de 2012. Gaceta Oficial de la República de Cuba, edición extraordinaria, n. ${ }^{\circ}$ 53, año 2012.

52 AzcuY, H., Análisis de la Constitución cubana y otros ensayos, Ed: Ruth Casa, La Habana, 2010, p. 51. 
párrafo segundo, que los bienes socialistas pueden transmitirse a personas naturales o jurídicas -tal título de transmisión sólo puede ser el de propietario privado individual-, categoría que hay que considerar a partir de aquí como constitucionalmente reconocida. El propio párrafo consigna el carácter excepcional en cuanto a la transmisión de estos bienes a personas naturales y jurídicas, y los requisitos establecidos para ello, reafirmándose que la irreversibilidad, no fue eliminada de manera absoluta, se tradujo en excepcionalidad, conforme a los términos del nuevo artículo 15.

La Constitución cubana reformada en 1992, regula como otra forma de propiedad, la de las empresas mixtas, sociedades y asociaciones extranjeras que se constituyen con acuerdo a la ley, con el objetivo de fundamentar jurídicamente la inversión extranjera en la economía nacional, luego del derrumbe del campo socialista y la crisis económica en la que se vio envuelta el país.

A partir de la reforma constitucional de 1992, con el reconocimiento del carácter reversible de la propiedad estatal (artículo 15) y la inserción de la propiedad de las empresas mixtas (artículo 23), cobran mayor fuerza las relaciones monetario mercantiles, mientras se abren nuevas interrogantes para las relaciones de planificación, las que no deben manifestarse igual ante sujetos y sectores que responden a formas de propiedad distinta. La planificación como mecanismo rector de la dirección económica se reorienta, desaparece el Plan Único de Desarrollo Económico Social y se transita hacia niveles importantes de descentralización de la planificación.

En la actualidad, se experimenta una heterogenización social, tendencia que se deriva principalmente del surgimiento de un sector reconocido como informal, donde aparecen como nuevas figuras: los propietarios-empleadores, pequeños propietarios de negocios de restaurantes y cafeterías, de talleres de reparación de automóviles, y otros, vinculados con formas de propiedad diferentes. En consecuencia con ello, el sector laboral se ha dividido entre los que se vinculan laboralmente con los sectores habituales y los que trabajan en los sectores emergentes, estos últimos, con nuevos métodos de estimulación del trabajo, que suponen ventajas materiales, monetarias o de otro tipo.

\section{ALGUNAS LÍNEAS PARA LA REFLEXIÓN EN POS DEL PERFECCIONAMIENTO DE LA CONSTITUCIÓN ECONÓMICA CUBANA}

El Sistema económico cubano tiene formulación constitucional socialista en cualquiera de los ámbitos objeto de análisis, en la esfera económica, en tanto, la propiedad socialista prevalece sobre otras formas de propiedad, se establece la administración estatal de forma directa sobre los bienes que integran la propiedad socialista, se regula la creación de empresas estatales y la dirección y control del comercio exterior, asentado en los principios de regu- 
lación, planificación y control estatal centralizado de los medios de producción y de la actividad económica. En el ámbito político social, al regularse como garantías materiales del modelo económico, que la soberanía reside en el pueblo, del cual dimana todo el poder del Estado (Art. 3). Todo ello fundamentado en los valores y principios de justicia social, de igualdad, el bienestar individual y colectivo, la libertad política, la solidaridad humana, la legalidad y la democracia socialistas (Arts. 1, 3, 10, 66y 68).

El texto Constitucional sometido a la dinámica de la vida no puede enmarcarse en normas estáticas e invariables dado que la realidad es siempre cambiante; debe existir coherencia entre las normas constitucionales, la realidad y la legislación complementaria, la cual desarrolla y viabiliza la realización de los mandatos constitucionales en la vida social. Cuba se encuentra en un momento de reformas administrativas y actualización de su modelo económico, guiadas por los Lineamientos de la Política Económica y Social del Partido y la Revolución aprobados en el VI Congreso del PCC de abril de 2011.

En el proceso de actualización del modelo económico cubano, se abre un espacio de reconfiguración de la relación Estado-Derecho y Economía, en el que los conceptos jurídicos irrumpen en el debate económico de forma protagónica. En ese sentido se impone como tema estratégico, reflexionar sobre el indispensable proceso de reforma constitucional e identificar al menos en líneas generales algunos aspectos conceptuales a repensar en materia de constitución económica, que combinen la propiedad social de los medios de producción, la producción social organizada por los trabajadores con el objetivo de satisfacer necesidades individuales y colectivas; locales y nacionales.

1. ¿Será viable reconocer constitucionalmente distintos tipos de propiedad, (6 tipos), de acuerdo a los titulares de las mismas, o resulta más conveniente calificar la propiedad a partir de los diferentes regímenes jurídicos aplicables? En la actualidad confluyen en un mismo espacio, bajo el régimen de derecho público, dos regímenes de propiedad diferentes.

2. El sector emergente requiere regulación constitucional expresa, reconocimiento que puede dirigirse en función del fomento y promoción de la actividad económica de carácter privada que realiza con interés público, en tanto constituye una fuente de empleo y de generación de riquezas para toda la sociedad.

3. La Constitución indistintamente denomina el tipo de propiedad fundamental, como propiedad socialista de todo el pueblo (Art. 14) y propiedad estatal socialista de todo el pueblo (Art. 15). Se impone concertar el lenguaje teniendo en cuenta el contenido esencial a garantizar y el alcance atribuible a la mencionada forma de propiedad, que en nuestra consideración debe convocar al reconocimiento de la propie- 
dad como «propiedad social», reflejo de una mayor profundización democrática.

4. Al amparo del socialismo, pueden coexistir diferentes formas de propiedad. Lo que debe quedar claramente definido, es la responsabilidad del Estado con el control, supervisión y fiscalización de los agentes (estatales y no estatales) que desarrollan su actividad en la sociedad, con el objetivo de ordenar las relaciones socioeconómicas.

5. A través del proceso de planificación habrá que potenciar la producción de alimentos y asegurar el dinamismo necesario de los sectores que pueden incrementar la riqueza económica del país: la industria, la energía y el turismo, entre otros ${ }^{53}$. La planificación en este nuevo contexto debe sustituir sus caracteres burocráticos por otros de esencia más democrática y articularse con el mercado.

«La sociedad a través del Estado revolucionario y de la participación social real debe solucionar paso a paso en función de mantener regulada la acción del mercado, las contradicciones entre la propiedad social y la privada, el mercado y la planificación, el interés individual y el interés social, el interés nacional y el del capital de las trasnacionales, contradicciones que pueden y deben convertirse en oportunidades para superar social y políticamente al mercado $\rangle^{54}$.

6. No consideramos que la cooperativa deba ser entendida como una forma de propiedad. De esa manera se reduce su naturaleza jurídica al patrimonio que administra. Las cooperativas son entes asociativos que deberán extender su regulación constitucional a otros sectores y formas de gestión.

7. Hoy día, el país está inmerso en cambios profundos, estratégicos, endógenos, del sistema económico. En materia de constitución económica algunos de los temas más trascendentales a debate, pudieran ser: la necesidad de regular la descentralización de las empresas estatales, la legalización de la pequeña y mediana empresa, potenciar espacios asociativos empresariales y territoriales (cooperativas, asociaciones municipales, la iniciativa privada, etc.), la cogestión y participación obrera, tendentes a reforzar proyectos sociales, y alcanzar una efectiva autonomía territorial, sobre la base de valores y alternativas más populares. Se requerirá una distribución de competencias con perspectiva descentralizadora, donde especialmente con vistas al control, pueda identificarse y exigirse la responsabilidad concreta, a la par que se garantiza el control popular efectivo de la gestión pública.

53 AA.VV., Aprendiendo economía en Cuba... Ob. cit. p. 19.

${ }^{54}$ Machado Rodríguez, D., Ob. cit. 
A nivel local el desarrollo debe partir de su potencial endógeno en función de las necesidades y características propias de cada localidad, y de principios como la auto organización, la autogestión y el autofinanciamiento, sobre bases jurídicas, económicas y políticas coherentemente definidas.

8. Es necesario diferenciar las funciones públicas de las puramente económicas, para lo cual se requeriría deslindar el régimen jurídico relacionado con la administración estatal directa, del aplicable a las empresas estatales.

9. Teniendo en cuenta que la normativa vigente establece la obligación de todos a contribuir con los gastos públicos, en tanto el tributo constituye un instrumento de política económica general y ha de responder a las exigencias del desarrollo económico y social del país, resulta indispensable, en pos de la coherencia del ordenamiento jurídico, regular de forma expresa en la Ley Fundamental ${ }^{55}$, el deber de tributar sobre la base de los principios de generalidad, equidad, capacidad económica, igualdad, progresividad y no confiscatoriedad, en correspondencia con los principios de justicia social e igualdad, de manera que se estimule el trabajo y la producción. Igualmente puede ser pertinente reconocer los fines de los tributos: recaudatorio y extrafiscal.

10. En la actualidad no están instrumentados mecanismos judiciales especiales para la protección de los derechos constitucionales. Regular soluciones a este fenómeno, tiene un impacto social que trasciende el ámbito jurídico en tanto responde a una necesidad social y al correcto funcionamiento del sistema político jurídico del país. Propiciar vías para la defensa de los derechos, constituye un instrumento de credibilidad y confianza en las estructuras estatales y políticas en la búsqueda de hegemonía, fortalezas y auto reproducción del sistema político.

En un contexto como el cubano, es difícil concretar dónde y en cuáles magnitudes sería permisible la desigualdad, cuán justificable pudiera ser, no solo económicamente, sino también jurídica y éticamente, dimensiones para las cuales no puede encontrar sustento. Resulta imprescindible definir el contenido y alcance del concepto de seguridad social básica. La seguridad social básica se refiere no solo al pago de las jubilaciones, la protección de las personas con discapacidad, la protección de la maternidad, la protección laboral, los ancianos sin amparo filial, los grupos vulnerables, sino también a los

${ }^{55}$ Estos fines y algunos de los principios se encuentran positivados en la Ley 113, pero su constitucionalización es algo importante. 
subsidios que se consideren necesarios y posibles en el terreno del suministro de agua, de electricidad, de alimentos básicos, de las medicinas, etc. y a las formas de organizar y canalizar ese subsidio ${ }^{56}$.

El desafío político social de base, permanece centrado en cómo perfeccionar el modelo económico, de manera que resulte más justo, eficiente y participativo, sin renunciar a las conquistas sociales alcanzadas, y multiplicar a su vez en las nuevas generaciones, el compromiso con el modelo socialista. En correspondencia con ello, la prestación de los «servicios públicos básicos» debe garantizarse sobre la base de los principios de objetividad, transparencia, no discriminación y proporcionalidad, reduciéndose al mínimo las distorsiones del mercado, si se prestaren de forma compartida, aunque, desde nuestro punto de vista, su garantía más esencial continúa siendo la permanencia de los mismos bajo un régimen de Derecho público de control y regulación.

Desde esta perspectiva, reconocer y promover formas no estatales en la gestión económica ${ }^{57}$ constituye un cambio de paradigma en la concepción sistémica socialista, pues exterioriza la necesidad de articular, componer y encauzar a sujetos con intereses disímiles, incorporar al ciudadano a la construcción de la realidad social, de manera que se socialice el poder y la economía.

\section{LA CONSTITUCIÓN ECONÓMICA SOCIALISTA EN EL SIGLO XXI}

El Socialismo del siglo XXI es concebido constitucionalmente ${ }^{58}$ como un sistema de organización social, política, normativa, económica y cultural que busca la libertad y la justicia, armonizando para ello los recursos materiales, institucionales e intelectuales de la sociedad, con el objeto de conseguir la igualdad de capacidades personales, la libertad de individuos y colectivos, la solidaridad entre los miembros de la comunidad, el respeto medioambiental,

56 «En el socialismo, el criterio determinante para la distribución, fuera de la educación, la atención médica y la seguridad social básica, tiene que ser el aporte individual a la sociedad, es decir, la cantidad y calidad del trabajo que cada quien haga. De igual modo, la sociedad en su conjunto desarrollará sus capacidades y dispondrá de recursos y riquezas en dependencia de la capacidad y posibilidades de producción de sus integrantes.» Firmeza de principios y cambio de mentalidad, Machado Rodríguez, D., Periódico Granma, 19 de Marzo de 1994, p. 3.

${ }^{57}$ Lineamiento de la política económica y social del Partido y la Revolución. VI Congreso del PCC, aprobado el 18 de abril de 2011, n. ${ }^{\circ} 2$ del Modelo de Gestión Económica., p. 10.

58 Monedero, J. C., «Socialismos en el siglo XXI. La experiencia de América Latina», en Coraggio, J. L.; LaVILLE, J-L., Reinventar la izquierda en el siglo XXI. Hacia un diálogo Norte-Sur, Universidad Nacional de General Sarmiento, Buenos Aires, 2014, p. 223. 
la paz entre las naciones y la defensa de la identidad de los pueblos; un modo de relaciones sociales de producción centrado en la convivencia solidaria y la satisfacción de necesidades materiales e intangibles de toda la sociedad, que tiene como base fundamental la recuperación del valor del trabajo como productor de bienes y servicios para satisfacer las necesidades humanas y lograr la suprema felicidad social y el desarrollo humano integral, para lo cual es necesario el desarrollo de la propiedad social sobre los factores y medios de producción básicos y estratégicos que permita que todos posean, usen y disfruten de su patrimonio, propiedad individual o familia, y ejerzan el pleno goce de sus derechos económicos sociales, políticos y culturales ${ }^{59}$.

En Venezuela, al igual que en otros países de América Latina, se han producido cambios para transformar el panorama político, económico e institucional, con destacada impronta constitucional. Muchos de los cambios se han dirigido hacia la democratización y descentralización del Estado con el objetivo de crear una relación de nuevo tipo entre el Estado y la Sociedad Civil, en el ámbito nacional regional y, sobre todo en el local. Esta transformación no está solamente dirigida a que el Estado reduzca su tamaño, ni a que los ciudadanos asuman responsabilidades propias de él; busca especialmente, profundizar en la conciencia sobre sus derechos ciudadanos, a la vez que aspira también a dotar, de legitimidad a las instituciones públicas.

Al respecto SEN subraya, que en el mundo de hoy existen dos maneras de percibir el desarrollo. Aquella que lo considera como un proceso esencialmente económico, una expansión acelerada y sostenida del Producto Interno Bruto per cápita, posiblemente con el requisito de que los frutos de esa expansión lleguen a todos los sectores de la población. En contraste, otra noción que lo considera como un proceso que enriquece la libertad real de los involucrados en la búsqueda de sus propios valores y cuya característica esencial es la expansión de la capacidad humana ${ }^{60}$.

Precisamente, luego de la promulgación en 1999 de la Constitución en la República Bolivariana de Venezuela quedó consagrado un nuevo paradigma de conceptualización, organización y funcionamiento del Estado, el cual consecuentemente determina un cambio en los mecanismos de gestión de los asuntos públicos. Se reconoce, que no es posible resolver los problemas del desarrollo, ni aprovechar sus oportunidades, sin la participación, el compro-

${ }^{59}$ Ley Orgánica del Poder Popular, artículo 8 numeral 14; Ley de la Comunas (Gaceta Oficial No 6.011 Extraordinario del 21-12-2010); Reglamento de la Ley Orgánica del Consejo Federal de Gobiernom artículo 3 (Gaceta Oficial No 39.416 de fecha 14 de mayo de 2010). Todas ellas referentes a la definición de Socialismo.

${ }^{60}$ LinARES, C., «Centralidad de la cultura en las dinámicas de transformación local», en Guzón Camporredondo, A., Desarrollo Local en Cuba. Retos y perspectivas, Ed: Academia, La Habana, 2006, pp. 112 y 113. 
miso y la corresponsabilidad de la Sociedad Civil. De esta forma, la eficacia en la acción del Estado depende en buena parte, del empuje con que actúen las organizaciones de la sociedad civil, para que los ciudadanos ejerzan sus derechos y cumplan con sus responsabilidades.

Por consiguiente, la Carta Magna de la República Bolivariana de Venezuela, aprobada mediante referéndum popular el 15 de diciembre de $1999^{61}$, define un nuevo modelo de las relaciones Estado - sociedad, fundamentado en una democracia participativa y descentralizada, tal como se señala en los artículos constitucionales 4 y 6: «La República Bolivariana de Venezuela es un Estado federal descentralizado en los términos consagrados por esta Constitución, y se rige por los principios de integridad territorial, cooperación, solidaridad, concurrencia y corresponsabilidad.

El sistema económico diseñado constitucionalmente en la República Bolivariana de Venezuela recibe una definición flexible, de carácter mixto, que económicamente pretende equilibrar los intereses estatales (en representación de la sociedad) con el mercado, consagrándose principios de justicia social, eficiencia, democracia, libre de competencia e iniciativa, defensa del ambiente, productividad y solidaridad, que sientan las bases de una economía de respeto a la acción individual, donde el Estado tiene un papel fundamental como regulador de la economía (Art. 299).

La Constitución de 1999 prevé la actividad económica conjunta del Estado y de la iniciativa privada en la consecución de los valores supremos. A los fines de garantizar el principio de la corresponsabilidad en la gestión pública de los gobiernos locales y estadales y desarrollar procesos autogestionarios y cogestionarios en la administración y control de los servicios públicos estatales y municipales se han creado nuevos sujetos de descentralización a nivel de las parroquias, las comunidades, los barrios y las vecindades.

La corresponsabilidad es un principio sugerente y novedoso que incorpora en su seno el texto constitucional. Parte del rompimiento de la clásica dicotomía liberal Estado-sociedad civil. La esfera pública no se circunscribe exclusivamente a la burocracia del Estado, pues allí se involucra directamente la sociedad organizada. La responsabilidad por los asuntos públicos no atañe exclusivamente al Estado, pues afecta a todos. No pueden atenderse ni resolverse sólo con las instituciones del Estado, pues exigen la participación organizada de la sociedad ${ }^{62}$.

${ }^{61}$ Constitución de la República Bolivariana de Venezuela GO n. 5 extraordinario, 24 de marzo de 2000.

${ }^{62}$ Combellas R., La Constitución de 1999 y la reforma política: implicaciones para la gobernabilidad democrática. VII Congreso Internacional del CLAD sobre la Reforma del Estado y de la Administración Pública, Lisboa, Portugal, 8-11 Oct. 2002. 
En este sentido Juan Carlos MonedERo considera, que el socialismo no puede construirse solo desde el Estado, y mucho menos desde el Estado burgués; la abolición de toda la propiedad privada es igualmente, tras cinco siglos de capitalismo, una simpleza que condena al estrangulamiento económico. Por último, la separación entre socialismo científico y socialismo utópico hurtó a la izquierda aquellos aspectos de la vida humana (curiosamente, los más gratificantes) que, por no ser materiales (amor, amistad, armonía, empatía, etc.), quedaron fuera de foco y fueron tirados por la borda. De cualquier forma, el socialismo del siglo XXI lo es porque se sitúa de manera clara y definida contra el capitalismo y la explotación que conlleva, incorporando a la transformación cualquier tipo de dominación ${ }^{63}$.

\section{CONSIDERACIONES FINALES}

La Unión Soviética, paradigma histórico para el resto de los países socialistas, en su concepción de socialismo real y Estado de todo el pueblo, se desvió a la larga, respecto al auténtico socialismo, abandonó en la práctica ideas muy arraigadas en la tradición marxista-leninista, el modelo en su realización práctica fue según opinión de TROTSKY ${ }^{64}$ un Estado obrero con deformaciones burocráticas.

En las diferentes etapas y contextos constitucionales particulares, se revelan contenidos específicos en la unidad dialéctica propiedad social-propiedad individual. Aunque continúa siendo determinante para la base económica socialista la constitucionalización del papel rector del Estado en la economía, a través de su intervención directa y el protagonismo de la propiedad socialista, es imprescindible la búsqueda de respuestas en función de cada construcción socialista particular, en correspondencia con las condiciones histórico-concretas que se deben razonar para elucidar las particularidades del fenómeno ${ }^{65}$.

${ }^{63}$ Monedero, Juan Carlos, Ob. cit.: p. 227.

${ }^{64}$ Trotsky, L., La revolución traicionada: ¿qué es y adónde va la URSS?, Fundación Federico Engels, Madrid, 2001, p. 82.

${ }_{65}$ Reputar como ciencia sabida al socialismo constituyó un equívoco reconocido: «Una conclusión que he sacado al cabo de muchos años: entre los muchos errores que hemos cometido todos, el más importante error era creer que alguien sabía de socialismo, o que alguien sabía de cómo se construye el socialismo». CASTRo RuZ, F., Discurso pronunciado en el acto por el aniversario 60 de su ingreso a la universidad, efectuado en el Aula Magna de la Universidad de La Habana, el 17 de noviembre de 2005. Versiones Taquigráficas-Consejo de Estado. Disponible: http://www.cuba.cu/gobierno/discursos/2005/esp/f171105e.html Transcurridos cinco años, el líder de la Revolución cubana reiteró la idea. CASTRo Ruz, Fidel: Mensaje a los estudiantes, 17 de noviembre de 2010. Disponible: http://www.cuba.cu/gobierno/reflexiones/2010/esp/m171110e.html. En va- 
Las Constituciones económicas socialistas, a tenor con los fundamentos marxistas, convocan a través de la formalidad técnico-legislativas a solucionar las contradicciones que se generan entre los procesos de enajenación y emancipación; entre los intereses colectivos y los privados. Muchas no lograron su realización plena en la dialéctica objetiva del proceso de producción -apropiación- reproducción de la vida social por los individuos. Los trabajadores debían de haber estado a la vanguardia del progreso social, como protagonistas del proceso productivo en su planificación, organización y ejecución.

En las constituciones, -sin dejar de ser socialistas por ello-, pueden coexistir, diferentes formas de propiedad. Su realización es posible, apegados a los fundamentos marxistas, condicionada a los requerimientos propios de la intervención estatal, de manera que sea posible ordenar las relaciones sociales de producción con criterios socialistas. El Estado debe ser responsable del control, supervisión y fiscalización de los agentes no estatales que desarrollan su actividad en la sociedad; a partir de la armonización de intereses entre el sector público y la esfera privada.

«Para alcanzar armonía entre el sector público y la esfera privada dentro de los marcos del sistema socioeconómico cubano, es necesario que los diferentes sujetos que producen y se apropian en la sociedad, contribuyan directamente a la socialización de la riqueza obtenida en un ámbito de descentralización política-administrativa, donde se conjugue la intervención del Estado con la participación ciudadana ${ }^{66}$.

Los fundamentos marxistas del constitucionalismo socialista propenden a una lógica aún no alcanzada, en la que la dialéctica producción-distribuciónconsumo se caracterice por la propiedad social de los medios de producción, (diferente a la propiedad estatal) y la producción social se organice por los trabajadores, con el objetivo de alcanzar el disfrute individual y colectivo, una democracia profunda ${ }^{67}$-, en la cual se incremente la capacidad de las personas de autogestionarse democráticamente, a través de mecanismos participativos -medios necesarios- para alcanzar el compromiso que asegure realmente, el protagonismo de los trabajadores, y el desarrollo consciente de una sociedad civil socialista.

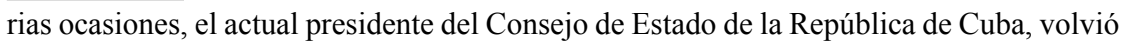
sobre aquellas palabras para significar su vigencia. CASTRO RUZ, R., Discurso pronunciado en las conclusiones de la primera sesión ordinaria de la VII Legislatura de la Asamblea Nacional del Poder Popular. Palacio de las Convenciones, La Habana, 11 de julio de 2008. Disponible: http:/www.cuba.cu/gobierno/rauldiscursos/2008/esp/r110708e.html. Todos ellos consultados el 2 de diciembre de 2013.

${ }^{66}$ Pérez Martínez, Y., Ob. cit.: p. 140.

${ }^{67}$ Lebowitz, M., El socialismo no cae del cielo. Un nuevo comienzo. Ed: Ciencias Sociales, La Habana, 2009. 
Es preciso ubicar en perspectiva política los cambios económicos en curso. Ese pensamiento que postula: «resolver primero el tema económico y después ver lo político» contiene la ingenuidad de separar la economía de la política. La única garantía de poder aspirar a mantener una orientación socialista de la economía radica en el predominio de la propiedad social sobre los medios fundamentales de producción y servicios, una legalidad que lo ampare y un Estado que la articule eficientemente, junto con una regulación colectiva de los trabajadores en cada unidad productiva o de servicios. Todo ello con el correlato ideológico de la actividad política y cultural que postule y promueva los valores humanistas del socialismo ${ }^{68}$.

\section{TITLE: The Socialist Constitution and economic fundamentals}

RESUMEN: Existe una relación dialéctica y compleja muy estrecha, entre politica, Derecho y economía, elementos que se articulan en distintos modelos como alternativas diferentes del ejercicio económico. La naturaleza de la economía que diseña el sistema socialista demanda la integración del Derecho a la vida económica. En ese contexto, los postulados de tipo socialista se caracterizan por la regulación, planificación y control central de la actividad económica, la existencia de decisiones de autoridad que debe erigirse sobre la base de las necesidades del ciudadano y por un sistema de propiedad, en el que prevalece la propiedad estatal sobre otros tipos de propiedad que con ella pueden convivir.

PALABRAS CLAVE: Constitución económica, sistema económico, propiedad, socialismo.

ABSTRACT: There is a very complex, narrow and dialectic relation between politics, Law and economics, elements that are articulated in different models as dissimilar alternatives in the economics exercise. The nature of the economy that designs the socialist system demands the integration of Law in the economy's life. In that context, the socialist's postulates are featured by the regulation, planning and central control for the economic activity, the existence of authority decisions must be based on the necessities of the citizens and by a property system, in which prevails the Estate property over the other types of property that may coexist with it.

KEY WORDS: Economic Constitution, economic system, property, socialism.

RECIBIDO: 03.06.2016

ACEPTADO: 22.06.2016

${ }^{68}$ Machado Rodríguez, D., ¿Es posible construir el socialismo en Cuba?, segunda edición, Ed: Pueblo y Educación, La Habana, 2006, pp. 91-92. 